\title{
Comparison of sealing ability of different obturation techniques in type II root canals
}

\author{
Bo-Kyung Park, Ho-Keel Hwang, Hyoung-Hoon Jo* \\ Department of Conservative Dentistry, School of Dentistry, Chosun University, Gwangju, Korea
}

\begin{abstract}
This study evaluated the sealing ability of obturation technique in type II root canal through the comparison of the presence of voids between the single-cone technique using calcium silicate-based sealer and continuous wave compaction technique using resin-based sealer. This study used 30 extracted human maxillary single-rooted premolars that were instrumented with rotary nickel-titanium instrument and randomly assigned to two groups. The root canals were obturated with either single-cone technique using calcium silicate-based sealer or with continuous wave compaction technique using resin-based sealer. The presence of voids in the samples in mesio-distal directions were evaluated using radiographs. There were more voids in the total volume and coronal third of the roots in the single-cone technique group than in the continuous wave compaction technique group. However, there was no significant difference in the percentage volume of voids in the middle and apical thirds of the roots between the two groups. Additionally, there was no significant difference between two groups with respect to external voids. Within limitation of this study, single-cone technique with calcium silicate-based sealer should be used very carefully in type II root canals.
\end{abstract}

Key Words: Continuous wave compaction, Root canal obturation, Single-cone technique, Voids

(c) This is an open-access article distributed under the terms of the Creative Commons Attribution Non-Commercial License (http://creativecommons.org/licenses/by-nc/4.0) which permits unrestricted noncommercial use, distribution, and reproduction in any medium, provided the original work is properly cited.

\section{INTRODUCTION}

The objective of root canal treatment is to clean and shape the pulp space, and completely obturate it with an appropriate filling material [1]. Appropriate root canal obturation prevents residual bacteria and their toxins from affecting the periapical tissue [2]. One of the major causes of endodontic failure is microleakage, which may occur between the gutta-percha and sealer. In many studies, inadequately obturated teeth showed a higher possibility of periapical lesion than those with adequate root canal filling
[3-5]. Gutta-percha is usually used with sealers to achieve a fluid-tight seal. Root canal sealers fill the spaces between the gutta-percha cones, as well as between the guttapercha and root canal walls [6]. Therefore, the root canal obturation technique and sealing ability of the root canal sealer are important factors determining the success of the root canal treatment.

Continuous wave (CW) compaction technique is one of the most widely used root canal obturation techniques. However, this approach may fail to prevent microleakage within the root canal system in some cases [7]. When the

Received May 16, 2019; Revised June 23, 2019; Accepted June 23, 2019

Corresponding author: Hyoung-Hoon Jo, Department of Conservative Dentistry, School of Dentistry, Chosun University, 309 Pilmun-daero, Dong-gu, Gwangju 61452, Korea.

Tel: +82-62-220-3848, Fax: +82-62-223-9064, E-mail: joyendo@hanmail.net 
gutta-percha is heated, it expands and contracts, possibly leading to formation of voids and gaps in the filling material [8]. Furthermore, this technique could generate some amount of pressure on the radicular dentin, causing vertical root cracks or fractures. To overcome these drawbacks, various root canal filling techniques, materials, and sealers have been developed and introduced in the dental market.

Recently, single-cone (SC) technique with newly developed calcium silicate-based sealer has been revived [9]. $\mathrm{SC}$ technique with conventional sealers is considered less effective in sealing root canals as compared to the $\mathrm{CW}$ compaction technique [10]. The newly developed calcium silicate-based sealers have reported good sealing ability and high biocompatibilty.

An endodontic sealer in the form of pre-mixed injectable paste was developed for clinical convenience. Endoseal MTA sealer (Maruchi, Wonju, Korea) is a calcium silicatebased sealer and a pure mineral trioxide aggregate (MTA) product with no resin added. It has good sealing capability with excellent flow, making it ideal for use in root canal obturation. The use of SC technique with Endoseal MTA sealer has been recommended by the manufacturer and some clinicians. However, presence of a number of voids in irregular shaped canals has been reported with the SC technique $[11,12]$. Moreover, the sealing ability to fill an oval or irregular canal space with SC technique clearly depends on the root canal form [9]. The SC technique with the use of this sealer has been recommended because of its flowability, biocompatibility, and dimensional stability. Additionally, bioceramic sealers can be used for filling root canals with or without the gutta-percha cones [13,14].

Until now, there are only few studies investigating the sealing ability of SC technique with calcium silicate-based sealers with respect to voids for various root canal configurations, such as Weine's type II root canals. Thus, the aim of this study was to evaluate the sealing ability in type II root canals by comparing the presence of voids between SC technique using calcium silicate-based sealer and CW compaction technique using resin-based sealer.

\section{MATERIALS AND METHODS}

\section{Sample preparation}

The research protocol of this study was approved by the Institutional Review Board of Chosun University Dental Hospital (CUDHIRB-1503-009). This study included 35 extracted human maxillary single-rooted premolars without caries, root resorption, restorations, immature apices, or fractures. Preliminary periapical radiographs in mesiodistal directions were recorded to evaluate the anatomy of the roots of the teeth. After radiographic examination, all samples with Weine's type II root canal configuration were included, while three teeth with other root canal types and two with severely calcified canals were excluded.

The remaining 30 teeth were decoronated using a diamond bur (TR13; Mani, Utsunomiya, Japan), and each root was adjusted to $12 \mathrm{~mm}$ length. A size 10 manual $\mathrm{K}$-file (Dentsply Maillefer, Ballaigues, Switzerland) was then inserted into the root canal until the file tip was just visible at the apex. The working length was set by subtracting $1 \mathrm{~mm}$ from this length.

All samples were shaped using Protaper Universal rotary instruments (Dentsply Maillefer) driven by a VDW motor (VDW GmbH, München, Germany) according to the manufacturers' instructions. The teeth were shaped using serial files from S1 to F2 with the crown-down technique. Final apical enlargement was performed using a size 30 or 35 manual K-file. During root canal preparation, irrigation was performed with $2 \mathrm{~mL} \mathrm{1.5 \%} \mathrm{sodium} \mathrm{hypochlorite}$ (NaOCl) delivered from a $3 \mathrm{~mL}$ syringe with a 27 -gauge endodontic side-vented needle. Endo Activator (Dentsply Maillefer) was used for 1 minute with $\mathrm{NaOCl}$ solution, and $1 \mathrm{~mL}$ of $10 \%$ ethylenediaminetetraacetic acid (EDTA) was used for final irrigation. Following this, the root canals of each sample were dried with sterile paper points (B\&L Biotech Inc., Fairfax, VA, USA).

\section{Root canal obturation}

All samples were divided randomly into two experimental groups ( $n=15$, each). Root canal sealers were prepared according to the manufacturer's recommendations. 
Group 1 (SC group) used SC technique with Endoseal MTA sealer. A master gutta-percha cone (B\&L Biotech Inc.) that corresponded to the final instrumentation size was selected. Endoseal MTA sealer was injected into the root canal, and the master gutta-percha cone was inserted into the root canal with a gentle pumping motion. For better penetration of the sealer into the root canal, ultrasonic vibration was used in an indirect fashion. Any excess guttapercha and sealer was removed using a heat carrier (Duo Alpha II; B\&L Biotech Inc.).

Group 2 (CW group) used CW compaction technique with Duo Alpha II and Duo Beta (B\&L Biotech Inc.) with AH Plus sealer (Dentsply Maillefer). The tip of the heat carrier was prepared to fit 3 to $4 \mathrm{~mm}$ short of the working length. A master gutta-percha cone corresponding to the final apical instrument size was adjusted until a tugback sensation was achieved. Its tip was then covered with the AH Plus sealer and inserted into the root canal with a gentle pumping motion. The heat plugger was inserted through the master cone with slight pressure up to the point 3 to $4 \mathrm{~mm}$ short of the working length. The power was turned off and the plugger was pushed apically for 10 seconds. An additional one second of heat application was done, and the plugger was extracted carefully. After removing the excess gutta-percha, thermoplasticized guttapercha injection was performed with Duo Beta in the middle and coronal thirds of the root canal. The top portion of the gutta-percha in the coronal thirds was condensed with the hand plugger.

After the root canal obturation procedure, all samples were stored at $37^{\circ} \mathrm{C}$ at $100 \%$ humidity for 5 days to ensure setting of the sealer.

\section{Radiographic image analysis}

Radiographs of the samples in mesio-distal directions were recorded to evaluate the presence of voids. Each radiographic image was evaluated using ImageJ $1.50 \mathrm{i}$ (National Institutes of Health, Bethesda, MD, USA). Each sample was divided into three regions, starting from the apical end of the root: level of 0 to $4 \mathrm{~mm}$ (apical), 4 to 8 $\mathrm{mm}$ (middle), and 8 to $12 \mathrm{~mm}$ (coronal). For each region, the mean volume of the obturating materials and voids were calculated. Furthermore, the voids were classified as external voids (along the canal walls) and internal voids (inside the filling materials) (Fig. 1).

\section{Statistical analysis}

The difference in mean volume of the obturating materials between the groups was compared using the student's t-test. Statistical analysis was performed using SPSS (version 18.0.0; SPSS Inc., Chicago, IL, USA). The differences were considered significant if the $p$-value was less than 0.01 .

\section{RESULTS}

The mean volume (percentage \pm standard deviation) of the root canal filling materials (gutta-percha and sealer) and voids (external and internal) are summarized in Table 1. No specimen was free of voids, and occurrence of voids was unpredictable in all samples.

The CW group showed smaller sized voids than the SC group in the total volume of the root canal. In the coronal third, the SC group showed more voids as compared to the $\mathrm{CW}$ group (Fig. 2). However, no significant difference in the percentage volume of voids was found in the middle and apical thirds. There was no significant difference found between the two groups with respect to external voids. The SC group had more internal voids than the CW group in the coronal third and total volume of the root canal. Presence of external or internal voids showed no certain
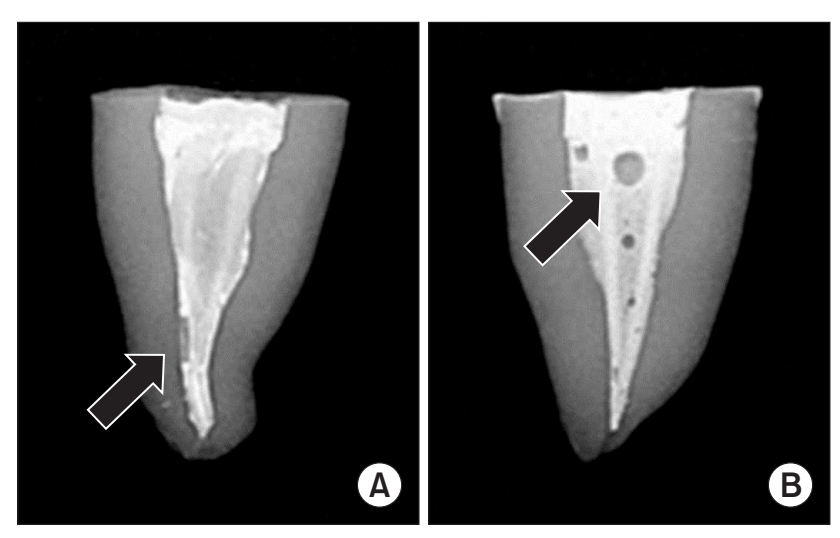

Fig. 1. Classification of voids. The arrow indicates external void (A) and internal void (B). 
tendency. In the $\mathrm{CW}$ group, percentage of voids increased from the coronal thirds to the apical thirds, but decreased in the middle thirds and increased in the apical thirds in the $\mathrm{SC}$ group. In both groups, the ratio of external voids was highest in the apical third.

Table 1. Mean volume of the voids in the radiographs for the different regions

\begin{tabular}{cccc}
\hline Region & Total voids & External voids & Internal voids \\
\hline Coronal third & & & \\
SC & $7.07 \pm 5.06^{\mathrm{a}}$ & $1.01 \pm 5.06$ & $6.06 \pm 4.97^{\mathrm{a}}$ \\
CW & $0.81 \pm 1.10^{\mathrm{a}}$ & $0.04 \pm 1.10$ & $0.77 \pm 0.15^{\mathrm{a}}$ \\
Middle third & & & \\
SC & $4.32 \pm 3.55$ & $0.61 \pm 3.55$ & $3.71 \pm 3.27$ \\
CW & $5.65 \pm 4.64$ & $0.72 \pm 4.64$ & $4.93 \pm 3.88$ \\
Apical third & & & \\
SC & $9.21 \pm 5.15$ & $4.17 \pm 5.15$ & $5.04 \pm 3.64$ \\
CW & $9.88 \pm 5.93$ & $4.16 \pm 5.93$ & $5.72 \pm 4.70$ \\
Total & & & \\
SC & $6.65 \pm 3.42^{\mathrm{a}}$ & $1.31 \pm 3.42$ & $5.34 \pm 3.21^{\mathrm{a}}$ \\
CW & $3.60 \pm 1.64^{\mathrm{a}}$ & $0.82 \pm 1.64$ & $2.78 \pm 1.42^{\mathrm{a}}$ \\
\hline
\end{tabular}

Values are presented as percentage \pm standard deviation.

SC, single-cone technique; CW, continuous wave compaction technique.

${ }^{a}$ Indicate statistically significant difference between groups $(p<0.01)$.

\section{DISCUSSION}

Radiography is the only way to evaluate the completeness of the root canal fillings in clinical situations. Moreover, only bucco-lingual projection or some degree of eccentric projection can be performed. However, a wellobturated radiograph in the bucco-lingual projection can disclose defects such as voids that are also visible in the mesio-distal projection [15]. In fact, these defects were also detected by other methods such as the dyepenetration test, and hence it is difficult to evaluate the success or failure of the root canal treatment only through radiographic analysis in the bucco-lingual direction. Conventional bucco-lingual projection may be of limited value when evaluating the quality of the root canal filling [16]. A large number of root canal fillings considered to be of good quality may actually be insufficiently sealed [15]. In this study, comparison of root canal fillings between two different techniques was performed by radiographic analysis in the mesio-distal direction for more detailed information.

Root canal filling material should prevent the penetration of microorganisms and toxins; however, there are chances of survival of microorganisms even after root canal treatment [17]. Residual bacteria can re-grow in the unfilled spaces, such as voids. Frequently, there are voids in the
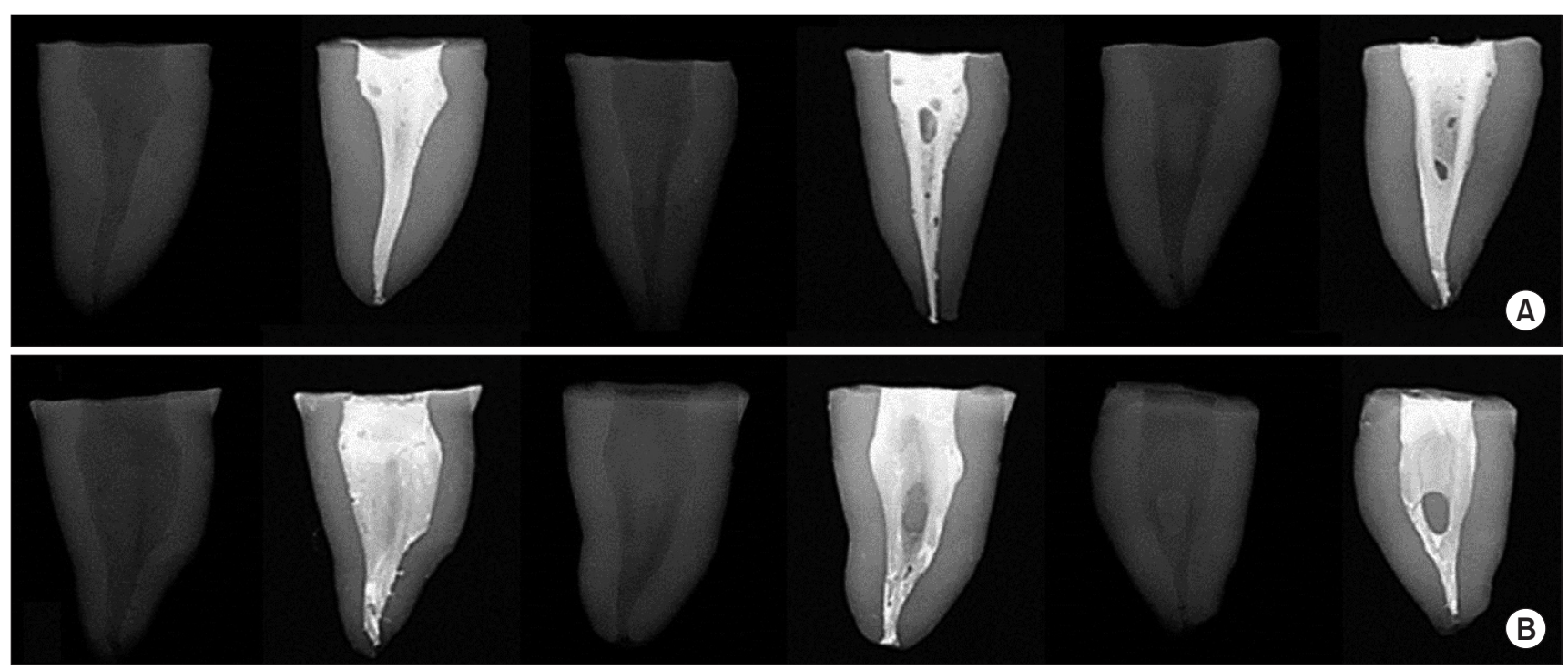

Fig. 2. Representative radiographic images of pre- and post-experiment in the two groups. (A) Single-cone technique (SC group) with Endoseal MTA sealer (Maruchi). (B) Continuous wave compaction technique (CW group) with AH Plus sealer (Dentsply Maillefer). 
root canal filling materials known as internal voids, and could be considered less clinically relevant because bacteria, if present, are confined in an unfavorable environment. On the other hand, voids along the canal walls, known as external voids, could be a cause of re-infection, because they are in contact with potentially infected canal walls [18]. In this study, the percentage volume of external voids that could affect the success and failure of the endodontic treatment showed no significant difference between the two groups.

Celikten et al. [19] reported that the number of voids showed no significant difference in samples filled by the lateral compaction and Thermafil techniques, whereas void volumes were slightly higher in the SC technique group. They also reported that the bioceramic sealers (EndoSequence BC sealer and Smartpaste bio) produced similar voids, which were the smallest in the apical thirds of root canals among all the sealers tested [19]. However, Moinzadeh et al. [20] reported that SC technique using calcium silicate cement produced lesser porosity than the lateral compaction method. In this study, the SC group showed more voids in the total volume and coronal thirds of the root canals than the $\mathrm{CW}$ group. No significant difference in the percentage volume of external voids was found in the root canal regions, but the internal voids were significantly larger in the SC group.

The two samples did not show complex root canal anatomy such as inter-canal connections. Total voids of the two specimens were measured very small $(0.89 \%$ and $0.68 \%$, respectively). It was considered easier to achieve dense filling in round single-rooted canals without anatomic complexity. Therefore, in a single-rooted canal, both filling methods were expected to give excellent results. However, in oval and broad root canals, it is hard to achieve perfect filling with SC technique. In this study, the SC group had more voids than the $\mathrm{CW}$ group in the coronal thirds. It is postulated that the wider root canal space, which does not allow a snug fit of the single cone, has higher potential for creation of voids. In other words, the more space left unfilled by the master cone, more the voids created. Therefore, the snug fit of the master cone along the prepared root canal space could be an important factor for successful root canal obturation when using the SC technique with calcium silicate sealer. The SC technique with Endoseal MTA sealer might be more efficient in small round canals than in large oval-shaped canals.

Anatomical variations, such as lateral canals, are most common in the apical thirds. Therefore, voids in the apical thirds may be more susceptible to re-infection. The presence of a gap between the filling material and lateral canal could be a factor in the root canal treatment failure [18]. Gandolfi et al. [21] reported that use of the MTA Flow sealer showed lesser voids in the apical third than that of $\mathrm{AH}$ Plus sealer, whereas similar voids were seen in the middle and coronal thirds. In this study, however, no significant difference in the percentage volume of voids between the $\mathrm{CW}$ and SC group was found in the apical thirds.

Improper and excessive pressure during root canal filling with CW compaction technique can lead to vertical root fracture and tooth loss [22,23]. SC technique may be less damaging to the tooth than lateral compaction and vertical condensation methods. Capar et al. [24] reported that the incidence of fractures using SC technique was lesser than that with conventional techniques, such as cold lateral and warm vertical compaction. Additionally, the SC technique was much faster to perform in clinical situations because of lesser procedures involved.

Conventional radiographic analysis has a limitation of producing a two-dimensional image. In fact, internal voids assessed in radiography could probably be external voids. Recently, micro-computed tomography (micro-CT) was able to evaluate the filling materials, voids, and tooth structures with higher accuracy [25]. Therefore, further studies using micro-CT will be required to compare sealing ability of SC technique with calcium silicate-based sealers.

The SC group showed more voids as compared to the $\mathrm{CW}$ group in the total volume and coronal thirds of the root canal. Within limitation of this study, SC technique with calcium silicate-based sealer should be used very carefully in type II root canals.

\section{ACKNOWLEDGEMENTS}

This study was supported by the research fund from Chosun University, 2017. 


\section{CONFLICTS OF INTEREST}

The authors declare that they have no competing interests.

\section{ORCID}

\author{
Bo-Kyung Park \\ https://orcid.org/0000-0001-8320-900X \\ Ho-Keel Hwang \\ https://orcid.org/0000-0003-3237-232X \\ Hyoung-Hoon Jo \\ https://orcid.org/0000-0003-3566-1821
}

\section{REFERENCES}

1. Vertucci FJ. Root canal anatomy of the human permanent teeth. Oral Surg Oral Med Oral Pathol 1984;58:589-599. doi: 10.1016/0030-4220(84)90085-9.

2. Michaud RA, Burgess J, Barfield RD, Cakir D, McNeal SF, Eleazer PD. Volumetric expansion of gutta-percha in contact with eugenol. J Endod 2008;34:1528-1532. doi: 10.1016/j.joen.2008.08.025.

3. Boucher Y, Matossian L, Rilliard F, Machtou P. Radiographic evaluation of the prevalence and technical quality of root canal treatment in a French subpopulation. Int Endod J 2002;35:229-238. doi: 10.1046/j.1365-2591.2002.00469. $\mathrm{x}$.

4. Kirkevang LL, Hørsted-Bindslev P. Technical aspects of treatment in relation to treatment outcome. Endod Top 2002;2:89-102. doi: 10.1034/j.1601-1546.2002.20106.x.

5. Segura-Egea JJ, Jiménez-Pinzón A, Poyato-Ferrera M, Velasco-Ortega E, Ríos-Santos JV. Periapical status and quality of root fillings and coronal restorations in an adult Spanish population. Int Endod J 2004;37:525-530. doi: 10.1111/j.1365-2591.2004.00826.x.

6. Sönmez IS, Oba AA, Sönmez D, Almaz ME. In vitro evaluation of apical microleakage of a new MTA-based sealer. Eur Arch Paediatr Dent 2012;13:252-255. doi: 10.1007/ bf03262880.

7. Magura ME, Kafrawy AH, Brown CE Jr, Newton CW. Human saliva coronal microleakage in obturated root canals: an in vitro study. J Endod 1991;17:324-331. doi: 10.1016/ S0099-2399(06)81700-0.

8. Peng L, Ye L, Tan H, Zhou X. Outcome of root canal obturation by warm gutta-percha versus cold lateral condensation: a meta-analysis. J Endod 2007;33:106-109. doi: 10.1016/j.joen.2006.09.010.

9. Gordon MP, Love RM, Chandler NP. An evaluation of .06 tapered gutta-percha cones for filling of .06 taper prepared curved root canals. Int Endod J 2005;38:87-96. doi: 10.1111/j.1365-2591.2004.00903.x.

10. Beatty RG. The effect of standard or serial preparation on single cone obturation. Int Endod J 1987;20:276-281. doi: 10.1111/j.1365-2591.1987.tb00627.x.

11. Bergmans L, Moisiadis P, De Munck J, Van Meerbeek B, Lambrechts P. Effect of polymerization shrinkage on the sealing capacity of resin fillers for endodontic use. J Adhes Dent 2005;7:321-329. doi: 10.3290/j.jad.a10763.

12. Weis MV, Parashos P, Messer HH. Effect of obturation technique on sealer cement thickness and dentinal tubule penetration. Int Endod J 2004;37:653-663. doi: 10.1111/ j.1365-2591.2004.00839.x.

13. Zhang W, Li Z, Peng B. Assessment of a new root canal sealer's apical sealing ability. Oral Surg Oral Med Oral Pathol Oral Radiol Endod 2009;107:e79-e82. doi: 10.1016/ j.tripleo.2009.02.024.

14. Zhang W, Li Z, Peng B. Effects of iRoot SP on mineralization-related genes expression in MG63 cells. J Endod 2010;36:1978-1982. doi: 10.1016/j.joen.2010.08.038.

15. Kersten HW, Wesselink PR, Thoden van Velzen SK. The diagnostic reliability of the buccal radiograph after root canal filling. Int Endod J 1987;20:20-24. doi: 10.1111/j.13652591.1987.tb00583.x.

16. Eckerbom M, Magnusson T. Evaluation of technical quality of endodontic treatment--reliability of intraoral radiographs. Endod Dent Traumatol 1997;13:259-264. doi: 10.1111/j.1600-9657.1997.tb00052.x.

17. Saunders WP, Saunders EM. Coronal leakage as a cause of failure in root-canal therapy: a review. Endod Dent Traumatol 1994;10:105-108. doi: 10.1111/j.1600-9657.1994. tb00533.x.

18. Somma F, Cretella G, Carotenuto M, Pecci R, Bedini R, De Biasi M, Angerame D. Quality of thermoplasticized and single point root fillings assessed by micro-computed tomography. Int Endod J 2011;44:362-369. doi: 10.1111/ j.1365-2591.2010.01840.x.

19. Celikten B, Uzuntas CF, Orhan AI, Orhan K, Tufenkci P, Kursun S, Demiralp KÖ. Evaluation of root canal sealer filling quality using a single-cone technique in oval shaped canals: an in vitro micro-CT study. Scanning 2016;38:133140. doi: 10.1002/sca.21249.

20. Moinzadeh AT, Zerbst W, Boutsioukis C, Shemesh H, Zaslansky P. Porosity distribution in root canals filled with gutta percha and calcium silicate cement. Dent Mater 2015;31:1100-1108. doi: 10.1016/j.dental.2015.06.009.

21. Gandolfi MG, Parrilli AP, Fini M, Prati C, Dummer PM. 3D micro-CT analysis of the interface voids associated with Thermafil root fillings used with AH Plus or a flowable MTA sealer. Int Endod J 2013;46:253-263. doi: 10.1111/ j.1365-2591.2012.02124.x.

22. Karapinar Kazandag M, Sunay H, Tanalp J, Bayirli G. Frac- 
ture resistance of roots using different canal filling systems. Int Endod J 2009;42:705-710. doi: 10.1111/j.13652591.2009.01571.x.

23. Meister F Jr, Lommel TJ, Gerstein H. Diagnosis and possible causes of vertical root fractures. Oral Surg Oral Med Oral Pathol 1980;49:243-253. doi: 10.1016/00304220(80)90056-0.

24. Capar ID, Saygili G, Ergun H, Gok T, Arslan H, Ertas H. Ef- fects of root canal preparation, various filling techniques and retreatment after filling on vertical root fracture and crack formation. Dent Traumatol 2015;31:302-307. doi: 10.1111/edt.12154.

25. Jung M, Lommel D, Klimek J. The imaging of root canal obturation using micro-CT. Int Endod J 2005;38:617-626. doi: 10.1111/j.1365-2591.2005.00990.x. 